\title{
Avaliação dos efeitos genotóxicos e contagem diferencial da série branca em indivíduos de Astyanax bimaculatus (Pices: Characidae) expostos a diferentes condições ambientais.
}

\author{
Evaluation of genotoxic effects and differential counting of the white cells in \\ individuals of Astyanax bimaculatus (Pices: Characidae) exposed to different \\ environmental conditions
}

\author{
Fernando Alves de Oliveira $\left.{ }^{*}{ }^{*}\right)$ \\ Tobias Pereira de Morais ${ }^{2}$ \\ Luiz Eduardo Aparecido Grassi ${ }^{3}$
}

\section{Resumo}

A contaminação de corpos hídricos como rios, córregos, lagos e águas subterrâneas podem afetar as populações humanas e de organismos que compõem a biota desses ambientes, sendo capaz de causar alterações fisiológicas e celulares nos indivíduos. A observação das alterações nos componentes celulares de organismos expostos a contaminantes ambientais utilizando metodologias específicas, como o teste do micronúcleo e de anomalias nucleares, é uma importante ferramenta de monitoramento, sendo utilizada em pesquisas básicas e estudo de impacto ambiental de larga escala. $\mathrm{O}$ objetivo de nosso estudo foi observar possíveis efeitos genotóxicos em indivíduos da espécie Astyanax bimaculatus (lambari), mantidos em condições ambientais distintas, sendo: tanque revestido de lona (um); caixa de fibra (dois); e caixa de fibra com cobertura (três). Utilizou-se o teste do micronúcleo (MN) e de anomalias nucleares (ANs) para avaliação de possíveis alterações celulares nos indivíduos, efeito genotóxico e a contagem diferencial da série branca para avaliação da saúde dos organismos. Foram encontrados MNs e ANs em todas condições ambientais avaliadas, com diferença significativa entre as condições um e três, quanto à frequência de $\mathrm{MN}$; com relação à frequência de $\mathrm{ANs}$, houve diferença entre um e três e entre dois e três, sendo a maior frequência de $\mathrm{MN}$ e ANs encontrada na caixa de fibra coberta. Os indivíduos da condição dois apresentaram maior frequência de linfócitos e no tanque de lona e na caixa coberta foram observado os maiores valores de monócitos e neutrófilos. Os resultados indicam que, mesmo em condições distintas, os indivíduos de $A$. bimaculatus apresentaram valores de alterações nucleares significantes, não sendo encontrado valores de leucócitos que pudessem indicar modificação na saúde dos organismos avaliados.

Palavras-chave: Ecotoxicologia. Monitoramento ambiental. Alterações nucleares.

1 Me.; Ciência e Tecnologia Ambiental; Universidade Federal da Grande Dourados, UFGD, Brasil; Atua nos seguintes temas: teste de micronúcleos in vivo e in vitro, teste de aberrações cromossômicas e teste de Ames; Coordenadoria Regional de Educação, Rua Hayel Bon Faker - 5470, Alto das Paineiras, CEP: 79826435 - Dourados, MS - Brasil; E-mail: fernandooliveira.bio@gmail.com (*) Autor para correspondências

2 Me.; Biologia; Universidade Federal da Grande Dourados, UFGD, Brasil; Atualmente é doutorando do Programa de Pós-Graduação em Ecologia e Conservação da Biodiversidade (Capes 6) pela UFPR; Rua XV de Novembro, 1299 Centro, CEP: 80060-000; Curitiba, PR - Brasil; E-mail: tobias_morais@hotmail.com

3 Dr.; Ciências Biológicas; Universidade Estadual Paulista Júlio de Mesquita Filho, UNESP, Brasil; Professor da Universidade Estadual de Mato Grosso do Sul; Universidade Estadual de Mato Grosso do Sul, Curso de Ciências Biológicas. Rodovia Dourados Itahum Km 12, Cidade Universitária, CEP:79804000 - Dourados, MS - Brasil E-mail: grassi@uems.br

Recebido para publicação em 21/08/2014 e aceito em 05/02/2019

\begin{tabular}{llllll}
\hline Ambiência & Guarapuava (PR) & v.14 n.3 & p.614-631 & Set/Dez 2018 & ISSN $1808-0251$
\end{tabular}




\section{Abstract}

The contamination of water bodies such as rivers, streams, lakes and groundwater can affect the human population and organisms that make up the biota of these environments, being able to cause physiological and cellular alterations in the individuals. The observation of the changes in the cellular components of organisms exposed to environmental contaminants using specific methodologies, such as the micronucleus test and nuclear anomalies, is an important monitoring tool, being used in basic research and large-scale environmental impact study. The objective of our study was to observe possible genotoxic effects in individuals of the species Astyanax bimaculatus (lambari) kept under different environmental conditions, being: tank covered with canvas (one); fiber box (two); and fiber box with cover (three). Micronucleus (MN) and nuclear abnormalities (ANs) were used to evaluate possible cellular alterations in the individuals, genotoxic effect, and the differential counting of the white series to evaluate the health of the organisms. MNs and $\mathrm{ANs}$ were found in all environmental conditions that were evaluated, with a significant difference between conditions one and three regarding to the frequency of $\mathrm{MN}$, with respect to the frequency of ANs there was a difference between one and three and between two and three, with the highest frequency of $\mathrm{MN}$ and ANs found in the covered fiber box. Subjects in condition two had a higher frequency of lymphocytes, and the highest values of monocytes and neutrophils were observed in the canvas tank and in the covered box. The results indicate that, even under different conditions, the individuals of A. bimaculatus presented values of significant nuclear alterations, and no leukocyte values were found that could indicate changes in the health of the evaluated organisms.

Keywords: Ecotoxicology. Environmental monitoring. Nuclear alterations.

\section{Introdução}

\section{Poluição e Efeitos aos Ecossistemas Aquáticos}

Ecossistemas aquáticos representam locais de grande importância, sendo essenciais para manutenção da biodiversidade e produtividade ecológica, além de proporcionar diversos recursos para a população humana. Dentre os diferentes usos da água, destaca-se a sua captação para consumo, uso industrial e na agropecuária, geração de energia, aquicultura, pesca e lazer (SOUZA et al., 2014).

O crescimento populacional vinculado à ampliação do uso da água nas mais diversas atividades têm resultado no aumento da sua contaminação, o que representa um potencial risco para a saúde humana e para a integridade dos ecossistemas aquáticos. $\mathrm{O}$ crescente aumento na contaminação de ambientes aquáticos, nas últimas décadas, tem origem em múltiplas fontes, tais como, desenvolvimento industrial, urbanização intensa, práticas agrícolas que introduziram grandes quantidades de diferentes substâncias biologicamente ativas na água, incluindo produtos químicos orgânicos e inorgânicos (BOLOGNESI; CIRILLO, 2014).

A bioacumulação de poluentes nos organismos aquáticos é outro fator de risco para estas comunidades, pois vários compostos liberados em níveis muito baixos no meio ambiente são persistentes e de difícil degradação, podendo, assim, acumularem-se nos tecidos desses organismos, chegando ao ponto de a concentração interna dos poluentes serem maiores que as do ambiente 
(BOLOGNES; CIRILLO, 2014). A falta de regulamentação de compostos emergentes, como drogas, produtos médicos, esteroides e hormônios, cosméticos, também representam um fator de risco para ecossistemas aquáticos (BOLEDA et al., 2009; SANTOS et al., 2010).

A liberação de uma infinidade de produtos químicos resulta na formação de misturas complexas, incluindo compostos de origem e seus produtos de transformação, o que pode resultar em diferentes condições sobre o ecossistema como, diminuição da diversidade biológica, aceleração ou redução dos processos tróficos, além de alteração interna dos organismos causando respostas fisiológicas anormais, como mudança no funcionamento de órgãos e nos estágios reprodutivos dos indivíduos (VÖRÖSMARTY et al., 2010; GINEBREDA et al., 2014). Tais aspectos reforçam a necessidade da aplicação de metodologias de avaliação da qualidade ambiental que avaliem além dos aspectos físico-químicos e considerem, também, o estado fisiológico e possíveis alterações em órgãos e células dos organismos.

\section{Ecotoxicologia e os Teste de Anomalias Nucleares}

Dentre as linhas de pesquisas que buscam o monitoramento ambiental em ambientes aquáticos, os estudos ecotoxicológicos possuem grande relevância. Esses métodos buscam, entre outros aspectos, realizar análises quantitativas e qualitativas que possam ser utilizadas no monitoramento da qualidade ambiental, através do diagnóstico dos parâmetros físicos, químicos e biológicos do ambiente, fazendo-se uma correlação das características do ambiente com possíveis alterações fisiológicas encontradas nos organismos presentes (ZAGATTO; BERTOLETTI, 2008; MORAIS; AZEVEDO, 2017). Assim, a ecotoxicologia representa um campo científico distinto que investiga o impacto de contaminantes químicos no ambiente em nível molecular, fisiológico, individual e ecológico (BEKETOV; LIESS, 2012; GALLOWAY, et al., 2017).

Nos estudos ecotoxicológicos podem ser realizadas avaliações tanto in loco - com uma população ou várias populações em um ambiente natural - quanto através de ensaios laboratoriais - bioensaios. Os ensaios laboratoriais podem ser realizados em ambientes controlados ou através da constituição de microcosmo. Um microcosmo caracteriza por representar as características do ambiente natural (água, plantas, sedimentos, animais, etc.) em um ambiente artificial (ARAGÃO; ARAÚJO, 2008).

Entre as metodologias analíticas utilizadas em estudos ecotoxicológicos estão as análises de efeitos genotóxicos, que são aplicadas quando existem suspeitas de alterações moleculares ou fisiológicas causadas pela presença de alguma substância química, como agrotóxicos, e/ou física, radiação por exemplo, que interfira em aspectos genéticos ou outros componentes celulares dos organismos (SALVADORI et al., 2003; UMBUZEIRO; ROUBICEK, 2008).

Consideram-se como metodologia de avaliação genotóxica o uso da análise de frequência de micronúcleo e de anomalias nucleares, que pode ser realizada com a utilização de células nucleadas da maioria dos tecidos. Em peixes, a análise da frequência de micronúcleo e de anomalias nucleares em eritrócitos são metodologias muito difundidas, sendo viável devido ao custo e ao tempo de análise (PHAN, et al., 2015). Nessa metodologia, é possível avaliar a presença de alterações em eritrócitos da circulação periférica dos organismos; no caso, o sangue pode ser obtido pela punção da artéria, sem que haja necessidade da eutanásia dos organismos (GRASSI, 2002; SUMMAK et al., 2010; ROCHA et al., 2011; PHAN, et al., 2015).

O teste do micronúcleo é um método desenvolvido primariamente para avaliar a habilidade de substâncias em induzir dano cromossômico estrutural e/ou numérico em células em estágio de divisão (SCHMID, 1975; SALVADORI et al., 2006). A técnica original desenvolvida por Boller 
e Schmid (1970) tinha como organismo modelo o hamster, sendo posteriormente adaptada por Hooftman e Raat (1982) para utilização laboratorial em peixes. A avaliação mutagênica utilizando o teste do micronúcleo é uma metodologia bem estabelecida, pois pesquisas têm utilizado essa técnica para detectar os efeitos da exposição a substâncias químicas mutagênicas em peixes de várias espécies in loco ou em laboratório (NAN et al., 2013; WALIA, et al., 2015; HALLARE et al., 2016, TUREK, et al., 2018).

Os micronúcleos (MNs) surgem a partir de fragmentos cromossômicos ou cromossomos inteiros que não são incorporados ao núcleo principal nas células filhas, durante a mitose, sendo possível visualizá-los como pequenos núcleos separados do núcleo principal, com tamanho que pode variar de $1 / 5$ a 1/100 do núcleo principal (PHAN et al., 2015). A ocorrência de MNs está relacionada à exposição da célula a alguma substância que cause quebras cromossômicas (clastogênicos) ou componentes celulares como fibras do fuso e que induzem aneuploidia (aneugênicos), podendo ser agentes químicos, físicos e biológicos relacionados a esses danos (SALVADORI et al., 2006; RIVERO-WENDT et al., 2013; PHAN et al., 2015).

As anomalias nucleares (ANs) foram relatadas por pesquisadores durante os estudos de frequência de micronúcleo, indicando que tais anomalias sejam consideradas durante a análise convencional de micronúcleos, pois, podem ser decorrentes também de uma resposta aos processos de citotoxicidade e genotoxicidade de alguns compostos (BOTELHO et al., 2015; POLLO et al., 2015; BRAHAM et al., 2017).

Carrasco et al. (1990) descreveram as alterações morfológicas no envelope nuclear de peixes, classificando tais alterações em: núcleo que apresenta uma pequena invaginação do envelope nuclear contendo eucromatina (“blebbed”); núcleo com invaginações maiores que o núcleo blebbed (“lobed”); e núcleo apresentando um corte evidente no material nuclear (“notched”). Há relatos da presença de tais anomalias em eritrócitos de peixes, em decorrência da exposição do organismo a contaminantes químicos tóxicos, genotóxicos, mutagênicos ou carcinogênicos (CARROLA et al., 2014; BOTELHO et al., 2015; POLLO et al., 2015; BRAHAM et al., 2017). Baršienė et al. (2010) sugerem que os micronúcleos e as células binucleadas estão relacionados à divisão celular, enquanto que as anormalidades nucleares morfológicas podem estar relacionadas à amplificação do DNA.

Os efeitos genotóxicos nos organismos podem ser avaliados utilizando uma ampla gama de estudos, in vitro e in vivo, porém, o teste de micronúcleos e de anomalias nucleares em eritrócitos ganhou popularidade em comparação aos outros ensaios citogenéticos de toxicidade aquática devido à sua sensibilidade, simplicidade e confiabilidade na detecção de danos no DNA (CARRASCO et al., 1990; AL-SABTI; METCALFE, 1995; ÇAVAS; KONEN, 2007; BOPP et al., 2008).

\section{Parâmetros Hematológicos}

No Brasil estudos hematológicos tiveram início com os trabalhos de Oria (1932), realizando análises morfológicas de eritrócitos de diferentes espécies de teleósteos fluviais (TAVARESDIAS; MORAES, 2004). Na década de 1960, iniciaram-se os estudos com espécies marinhas com os trabalhos de Bastos (1966) e Pitombeira e Martins (1966). Os estudos hematológicos de teleósteos retornam a ter importância na década de 1980, com Ranzani-Paiva (1981), dando continuidade a partir de então, sendo ainda hoje uma das principais referências dessa área. 
A principal aplicação dos estudos de padrões sanguíneos está relacionada ao diagnóstico e prognóstico de condições mórbidas em populações de peixes, sendo aplicados principalmente em estudos com animais de interesse econômico, geralmente em pisciculturas (HENRY et al., 2015; JERÔNIMO et al., 2015). Os parâmetros hematológicos de peixes têm sido uma importante análise em pisciculturas, sendo utilizados como indicadores do estado fisiológico dos organismos, permitindo uma intervenção mais específica para o controle de patologias e de possíveis estresses de manipulação (HENRY et al., 2015; OBA-YOSHIOKA et al., 2017).

Nos estudos hematológicos, a avaliação dos elementos da série vermelha (eritrocítica) permite inferir a condição nutricional do organismo, além de outros fatores - como no caso de exposição a agentes tóxicos - já as análises de elementos da série branca (leucocitária), que estão relacionadas ao sistema imune, permite que seja avaliada a presença de processos infecciosos ou de outro tipo de estresse. A análise da camada leucocitária é a principal metodologia utilizada em estudos de análises clínicas, considerando, neste caso, tanto a avaliação de organismos aquáticos quanto as avaliações clínicas em humanos (TESKE, 2010).

O principal interesse nos elementos da série branca sanguínea está relacionado à sensibilidade desses elementos, à presença de patógenos e outros tipos de estresses no organismo. O método mais utilizado para estudos com estes elementos é a contagem diferencial de células leucocitárias, utilizando principalmente os monócitos, neutrófilos, basófilos e linfócitos. Tavares-Dias e Moraes (2004) ressaltam a dificuldade na classificação dos leucócitos, porém, os valores encontrados por estas variáveis permitem inferir sobre o estado de saúde do organismo.

O presente trabalho teve como objetivo utilizar a técnica do micronúcleo e de anomalias nucleares para monitorar exemplares de Astyanax bimaculatus (lambari) mantidos em diferentes condições ambientais, buscando-se observar as possíveis alterações nas frequências dessas alterações nucleares em decorrência das características de cada ambiente, sendo avaliadas ainda, as condições imunológicas dos animais através da contagem diferencial da série branca.

\section{Material e Métodos}

\section{Condições ambientais e experimentais}

O presente trabalho foi realizado na área experimental do Laboratório de Ecofisiologia (LEF) da Universidade Estadual de Mato Grosso do Sul (UEMS), Campus de Dourados/MS (22 $\left.11^{\circ} 84^{\prime \prime} \mathrm{S} ; 5^{\circ} 55^{\prime} 82^{\prime \prime} \mathrm{W}\right)$. As matrizes de Astyanax bimaculatus foram inicialmente obtidas em coletas realizadas em corpos d'água da Bacia do Rio Paraná, Município de Dourados/MS e regiões próximas, sendo mantidas as mesmas populações há 12 anos em tanques artificiais na área experimental. Os indivíduos avaliados neste estudo foram coletados da própria área experimental do LEF.

Os indivíduos de $A$. bimaculatus foram mantidos em três condições ambientais distintas. $\mathrm{O}$ primeiro ambiente foi em um tanque de piscicultura (de $10 \times 5 \times 1 \mathrm{~m}$ ), escavado e revestido com lona plástica, em condições próximas a um ambiente lacustre, com a presença de outras espécies de peixes e plantas aquáticas.

$\mathrm{O}$ segundo e o terceiro ambientes foram em caixas de fibra, com capacidade de $500 \mathrm{~L}$ cada, uma caixa (condição ambiental dois) exposta à iluminação natural e outra caixa (condição ambiental três) foi coberta para diminuir a entrada de luz solar nesse ambiente. $\mathrm{O}$ ambiente dois 
seguiu parte das características do primeiro ambiente, porém sendo em escala menor e sem a presença de outras espécies de peixes, apenas plantas aquáticas foram introduzidas nessa caixa. No ambiente três, só foram colocados os peixes, sem a introdução de plantas e outras espécies, num total de 65 exemplares de $A$. bimaculatus em cada caixa de fibra.

$\mathrm{O}$ abastecimento de água nas três condições ambientais foi realizado através do reservatório do campus, sendo a água proveniente de captação subterrânea. Em todos os locais de criação foi mantida a oxigenação natural, sem a utilização de bombas ou mecanismos de aeração, e a alimentação dos indivíduos teve como base proteína animal e vegetal (minhocas, caramujos e farinha de milho).

\section{Coleta dos Indivíduos}

A coleta dos exemplares de $A$. bimaculatus foi realizada de forma diferente em cada ambiente, considerando o tamanho de cada local. Assim, na condição um (tanque de piscicultura), foi utilizada rede de arrasto (picaré) e, nas condições ambientais dois e três (caixas de fibra) utilizou-se uma peneira. De cada local, foram coletados 25 indivíduos, sendo, posteriormente, transportados até o LEF, para realização da coleta de sangue da artéria caudal.

\section{Amostragem e Análise}

Para a confecção das lâminas hematológicas utilizaram-se seringas hipodérmicas de vidro de $3 \mathrm{~mL}$ e agulhas com anticoagulante (heparina), metodologia adaptada de Svobodova et al. (1991). O sangue foi retirado por punção da artéria caudal (GRASSI, 2002). Após a retirada das alíquotas, os peixes foram alocados em um segundo tanque, que não fazia parte dos experimentos.

O esfregaço sanguíneo foi montado em lâmina de ponta fosca, o procedimento foi realizado através da aplicação de uma gota de sangue próxima à ponta fosca e, com auxílio de outra lâmina, encostada na borda da gota de sangue, com inclinação aproximada de $45^{\circ}$, o sangue foi direcionado à direção oposta da ponta fosca em um único movimento, até o fim da borda da lâmina inferior (GRASSI, 2002).

Para coloração dos esfregaços utilizou-se a Reação de Feulgen - hidrólise em $\mathrm{HCl} 5 \mathrm{~N}$ (temperatura ambiente) durante 20 min, lavagem em água destilada $\left( \pm 5^{\circ} \mathrm{C}\right)$, imersão em Reativo de Schiff (120 min) à temperatura ambiente (escuro), lavagem em água corrente (10 min), lavagem rápida em água destilada, secagem à temperatura ambiente e imersão em solução de Fast-Green ácido por $1 \mathrm{~min}$, sendo as lâminas lavadas com água destilada e secadas em temperatura ambiente (GRASSI, 2002).

A frequência de micronúcleos (MNs) em eritrócitos da circulação periférica foi determinada segundo a metodologia proposta por Schmid (1975). As anomalias nucleares (ANs) foram determinadas segundo a metodologia de Carrasco et al.(1990). O efeito genotóxico foi considerado válido para lâminas que continham, no mínimo, três células em 1.000 com a presença de $\mathrm{MN}$ e/ou $\mathrm{AN}$, desconsiderando estruturas refringentes. $\mathrm{Na}$ contagem foram considerados apenas eritrócitos 
individualizados, com formato oval e de boa visualização. A contagem das 1.000 células de cada amostragem foi realizada em microscopia óptica, com resolução de 10x125 em imersão.

A contagem diferencial de elementos da série branca foi realizada através da observação em microscópio óptico de 100 células de leucócitos por lâmina (TESKE,2010). A caracterização dos leucócitos seguiu a metodologia descrita em Ranzani-Paiva (1981), Roberts (1981) e TavaresDias e Moraes (2004).

O teste estatística foi realizado através da análise de variância ANOVA e significância de Tukey 95\%, sendo considerado significativo em todas as análises o valor de $\mathrm{p}<0,05$, sendo utilizado o programa BioEstat 5.3 para as análises (AYRES et al., 2011).

\section{Resultados e Discussão}

\section{Teste do Micronúcleo e de Anomalias Nucleares}

Os peixes têm sido considerados bons bioindicadores de ecossistemas aquáticos (ROCHA et al., 2011). Além disso, vários estudos demonstraram que os peixes são organismos sensíveis, sendo adequados para a detecção de agentes genotóxicos (ANBUMANI; MOHANKUMAR, 2012; OMAR et al., 2012; NAN et al., 2013; WALIA et al., 2015; HALLARE et al., 2016, TUREK et al., 2018).

Neste trabalho foram encontrados micronúcleos (MNs) e anomalias nucleares (ANs) em todos os ambientes avaliados (Figura 1). Quando comparadas as análises de correlação estatística, houve diferença significativa $(\mathrm{p}<0,05)$ entre as condições ambientais um e três quanto à frequência de $\mathrm{MNs}_{\mathrm{s}}$ (Tabela 1), e entre as condições ambientais um e três e entre dois e três quanto à frequência de $\mathrm{AN}_{\mathrm{N}}$ (Tabela 2).

Figura 1 - Aspectos de eritrócitos em sangue periférico de $A$. bimaculatus observados nos ambientes: imagens de núcleo normal (A), micronúcleo (BC) e; anormalidades nucleares ( $\mathrm{D}$ a $\mathrm{H})$ : binucleadas (D), vacuolated (E), notched (FGH).

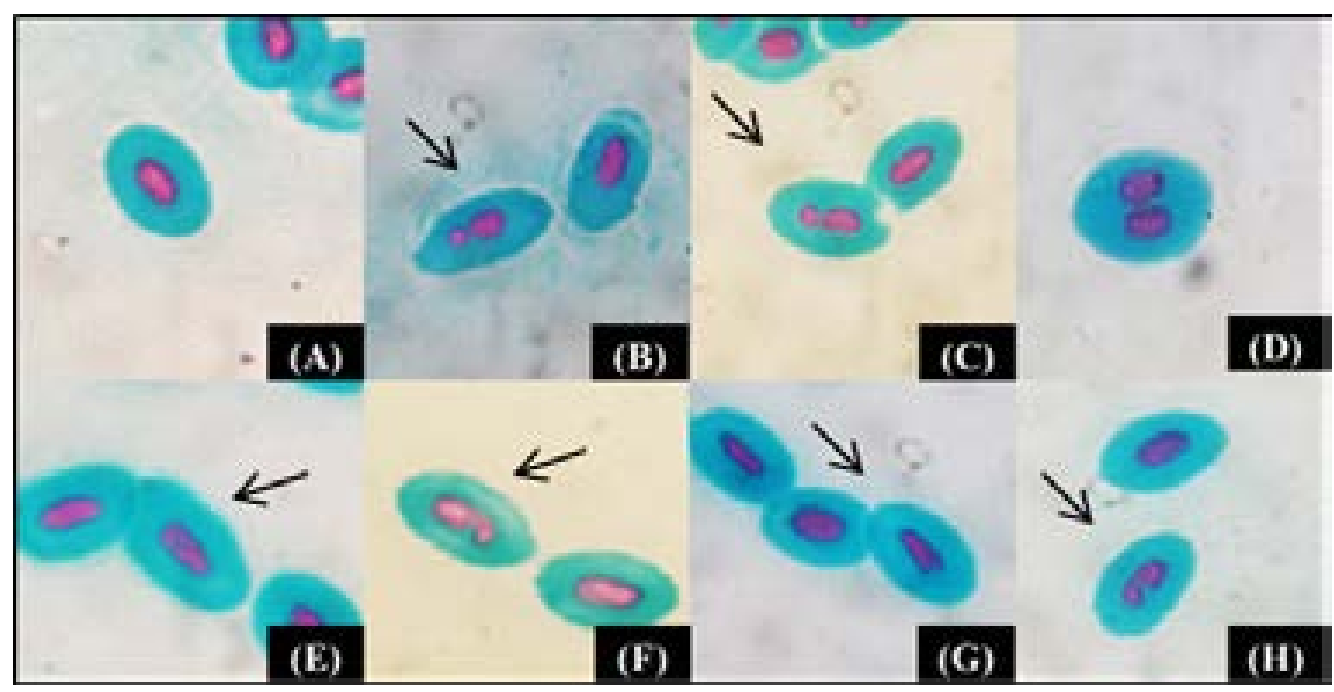

Fonte: Oliveira. 
A maior frequência de $\mathrm{MN}$ s observada, em média, foi na caixa de fibra coberta (condição ambiental três) e a menor no tanque de psicultura (condição ambiental um) (Tabela 1). Deve-se ressaltar que, de maneira geral, as médias encontradas nos ambientes foram menores que o valor considerado como indicativo de efeito genotóxico, ou seja, menos de três células em média das 1.000 células analisadas por indivíduo apresentaram micronúcleos. Porém, estes valores não devem ser subestimados, pois, os ambientes apresentaram valores significativos para outras alterações nucleares.

Tabela 1. Frequência de micronúcleos em eritrócitos de $A$. bimaculatus, apresentados em valores absolutos, médias e desvio padrão (MED/ DESV.P) e percentuais das amostragens nos ambientes, $n=25$.

\begin{tabular}{cccccc}
\hline Ambientes & $\begin{array}{c}\text { Número de } \\
\text { exemplares } \\
\text { com MN }\end{array}$ & $\begin{array}{c}\text { MED/ } \\
\text { DESV.P de } \\
\text { MN }\end{array}$ & $\begin{array}{c}\text { Porcentagem } \\
\text { de exemplares } \\
\text { com MN (\%) }\end{array}$ & $\begin{array}{c}\text { Exemplares } \\
\text { com número } \\
\text { significativo } \\
\text { de MN* }\end{array}$ & $\begin{array}{c}\text { Porcentagem } \\
\text { de exemplares } \\
\text { com número } \\
\text { significativo } \\
\text { de MN (\%) }\end{array}$ \\
\hline 1 & 13 & $0,72 \pm 0,82 \mathbf{a}$ & 52 & 1 & 4 \\
2 & 15 & $1,96 \pm 2,61 \mathbf{a b}$ & 60 & 6 & 24 \\
3 & 17 & $2,48 \pm 2,85 \mathbf{b}$ & 68 & 11 & 44 \\
\hline
\end{tabular}

Letras diferentes indicam diferença significativa pelo teste de Tukey $(p<0,05)$ entre os ambientes. *Número de indivíduos com três ou mais células em 1.000, com a presença de micronúcleo.

A avaliação da frequência de MNs, por si só, já apresenta resultados relevantes quanto à estimativa de genotoxicidade. Silva et al. (2016) realizaram o biomonitoramento in situ de rios da região de Catalão, Sudeste de Goiás, Brasil, em pontos sob influência da área urbana, agricultura e indústria de fertilizantes, utilizando peixes dos gêneros Astyanax sp. e Characidium sp. que habitam esses locais, sendo possível determinar os locais que mais influenciaram na prevalência de MNs e as espécies mais sensíveis ao zinco e cromo, sendo respectivamente Astyanax sp. e Characidium sp.

Quanto à frequência de $\mathrm{ANs}$, no presente estudo, foram encontradas as seguintes anomalias: células com mais de um núcleo (binucleadas); núcleo perfurado (vacuolated) e; núcleos com alterações morfológicas (notched). Em todos os ambientes foram encontrados valores significativos para as anomalias (Tabela 2), sendo a condição ambiental três a que apresentou maior frequência, caso em que todos os indivíduos apresentaram as anomalias. 
Tabela 2. Anomalias nucleares em eritrócitos de $A$. bimaculatus, apresentados em valores absolutos, médias e desvio padrão (MED/DESV.P) e percentuais das amostragens nos ambientes, $n=25$.

\begin{tabular}{cccccc}
\hline Ambientes & $\begin{array}{c}\text { Número de } \\
\text { exemplares } \\
\text { com AN }\end{array}$ & $\begin{array}{c}\text { MED/ } \\
\text { DESV.P de } \\
\text { AN }\end{array}$ & $\begin{array}{c}\text { Porcentagem } \\
\text { de exemplares } \\
\text { com AN (\%) }\end{array}$ & $\begin{array}{c}\text { Exemplares } \\
\text { com numero } \\
\text { significativo } \\
\text { de AN* }\end{array}$ & $\begin{array}{c}\text { Porcentagem } \\
\text { de exemplares } \\
\text { com número } \\
\text { significativo de } \\
\text { NA (\%) }\end{array}$ \\
\hline 1 & 22 & $3,04 \pm 2,19 \mathbf{a}$ & 88 & 14 & 56 \\
2 & 24 & $5,72 \pm 3,94 \mathbf{a}$ & 96 & 17 & 68 \\
3 & 25 & $10,2 \pm 5,08 \mathbf{b}$ & 100 & 25 & 100 \\
\hline
\end{tabular}

Letras diferentes indicam diferença significativa pelo teste de Tukey $(p<0,05)$ entre os ambientes. *Número de indivíduos com três ou mais células em $1.000 \mathrm{com}$ a presença de anomalia nuclear.

Segundo Cavalcante et al. (2008) a frequência de ANs é considerada como o indicador menos eficaz da genotoxicidade. Porém, tais anomalias têm sido utilizadas em diversos trabalhos como bons indicadores de genotoxicidade em peixes (BARŠIENE் et al., 2010; CARROLA et al., 2014; BOTELHO, et al., 2015; BRAHAM, et al., 2017). Osman e Harabawy (2010) observaram uma correlação entre as frequências de $\mathrm{MNs}$ e $\mathrm{ANs}$, sugerindo a importância da análise conjunta destes dois parâmetros, sendo considerados potenciais biomarcadores nucleares.

As alterações nucleares (MNs e ANs) são consideradas como uma resposta a exposição do organismo a alguma substância genotóxica ou ao estresse (CAMPANA et al., 1999; GRASSI, 2002; FERRARO et al.,2004; GALINDO; MOREIRA, 2009; SOUZA et al., 2014; BOTELHO, et al., 2015; POLLO, et al., 2015; BRAHAM, et al., 2017). Assim, considerando os valores de $\mathrm{MNs}$ e ANs encontrados no presente trabalho, todas as condições ambientais apresentaram respostas significativas à presença de um ou mais agentes genotóxicos. Ressaltando-se que, no presente trabalho foi considerado o valor já estabelecido para a frequência de micronúcleos na avaliação do efeito genotóxico como parâmetro para os valores de anomalias nucleares, ou seja, valor considerado significativo quando três ou mais células em 1.000 do indivíduo apresentaram a anomalia.

Segundo Melo et al. (2013), a análise de efeito genotóxico com a utilização dos testes de MNs e ANs permite verificar os potenciais efeitos adversos causados por compostos tóxicos no ambiente, sendo que, em caso de contaminação tóxica podem influenciar a qualidade de vida dos organismos expostos, bem como afetar possíveis consumidores. Assim, pode-se dizer que tais metodologias são importantes para utilização em estudos de monitoramento da qualidade ambiental.

Foi observada elevada frequência de micronúcleos e de anomalias nucleares em espécies de peixes dos Grandes Lagos nos Estados Unidos, sendo encontrada diferenças no número de alterações entre as espécies e entre os indivíduos de diferentes locais, foi possível observar também a relação dessas alterações com a prevalência de tumores de pele e fígado (BRAHAM, et al., 2017). Os Grande Lagos são caracterizados por receberem misturas complexas resultantes de atividades próximas, em cada ponto dessa região há o despejo de diferentes compostos, o que influenciou na concentração das alterações encontradas, indicando assim que estas misturas apresentam maior potencial genotóxico conforme a composição que possuíam (BRAHAM, et al., 2017). 
$\mathrm{O}$ valor de $\mathrm{MNs}$ e $\mathrm{ANs}$ encontrado na caixa de fibra coberta, significativamente diferente quando comparado aos outros ambientes, pode ser um indicativo que as condições desse ambiente - menor incidência de luz solar, exposição direta a água de abastecimento, menor crescimento de microrganismos (fito e zooplâncton) - podem ter influenciado na maior frequência de alterações nucleares. As características dessa condição ambiental devem ser consideradas como fator importante pois, diversos fatores podem diminuir a carga tóxica dos compostos, a exemplo do efeito da degradação biológica, realizada por microrganismos, bem como o efeito direto da luz solar sobre tais elementos (fotólise), ambos os exemplos podem resultar na alteração da conformação molecular dos compostos tóxicos, podendo reduzir seu potencial de toxicidade (ZAGATTO; BERTOLETTI, 2008).

\section{Contagem Diferencial de Leucócitos}

Os leucócitos são as células responsáveis pela defesa humoral e celular dos peixes, sendo formados por diferentes linhagens celulares, podendo ser diferenciados morfologicamente pela presença ou ausência de granulação, bem como pelas suas características morfológicas (TAVARES-DIAS; MORAES, 2004). As células brancas utilizam a via sanguínea para realizar o monitoramento de possíveis infecções e danos teciduais nos organismos, atuando dentro dos vasos sanguíneos e no meio intersticial.

Em nosso trabalho foi possível observar as células da série branca utilizando a coloração para contagem de micronúcleos, Reação de Feulgen. Foram identificados e caracterizados na contagem diferencial em $A$. bimaculatus: linfócitos, neutrófilos, monócitos e basófilos (Figura 2). Os valores absolutos e as médias são apresentados na tabela 3.

O número de leucócitos varia entre família, gênero e espécies de peixes e de acordo com o ambiente em que se encontram (TAVARES-DIAS; MORAES, 2004). No presente trabalho, os valores encontrados para os diferentes leucócitos estão dentro dos valores citados na literatura para família Characidae, a exemplo dos linfócitos que podem variar percentualmente entre 19,7 a 95,5 por cento nos peixes (TAVARES-DIAS; MORAES, 2004), sendo encontrados entre 78,72 e 90,76 por cento em nosso trabalho.

\section{Figura 2 - Tipos celulares da série branca encontrados em Astyanax bimaculatus:} Linfócito (Lf); Monócito (Mn); Neutrófilo (Nt); Basófilo (Bs).

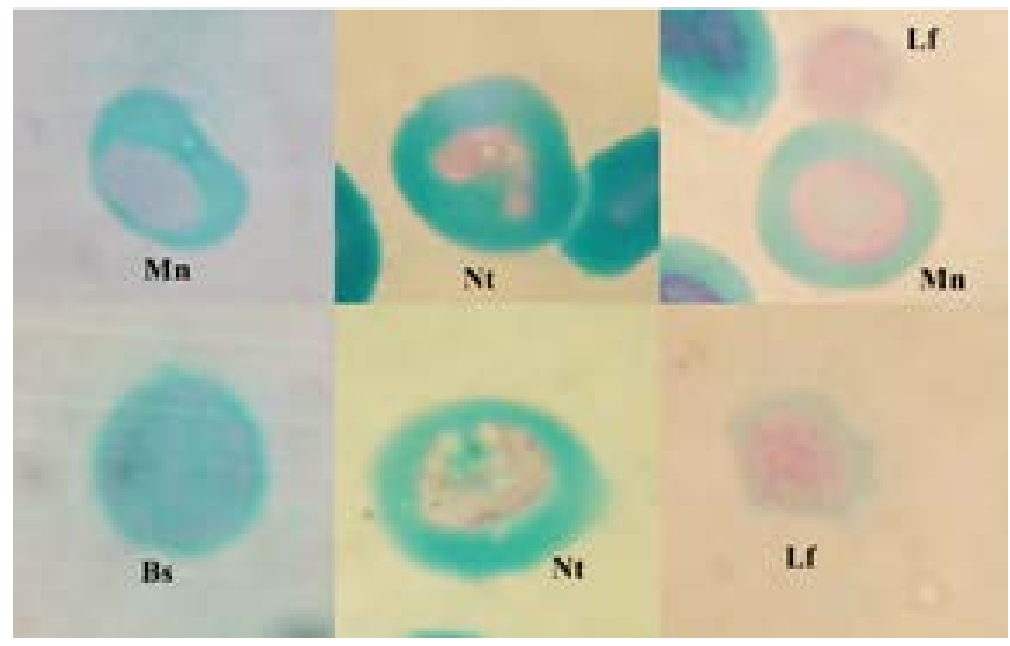

Fonte: Oliveira. 
Tabela 3. Tipos celulares encontrados em $A$. bimaculatus nos diferentes ambientes, sendo apresentados em valores totais e médias com desvio padrão.

\begin{tabular}{cccc}
\hline Tipos celulares & Ambiente $\mathbf{1}$ & Ambiente 2 & Ambiente 3 \\
\hline \multirow{2}{*}{ Linfócitos } & 1968 & 2269 & 2059 \\
& $78,72 \pm 13,93 \mathbf{a}$ & $90,76 \pm 6,45 \mathbf{b}$ & $82,36 \pm 10,19 \mathbf{a}$ \\
\cline { 2 - 4 } Monócitos & 414 & 174 & 352 \\
& $16,56 \pm 11,61 \mathbf{c}$ & $6,96 \pm 4,90 \mathbf{d}$ & $14,08 \pm 6,71 \mathbf{c}$ \\
\cline { 2 - 4 } Neutrófilos & 110 & 51 & 83 \\
& $4,40 \pm 3,74 \mathbf{e}$ & $2,04 \pm 2,27 \mathbf{f}$ & $3,32 \pm 3,85 \mathbf{e}$ \\
\cline { 2 - 4 } Basófilos & 8 & 6 & 6 \\
& $0,32 \pm 0,61 \mathbf{g}$ & $0,24 \pm 0,58 \mathbf{g}$ & $0,24 \pm 0,81 \mathbf{g}$ \\
\hline
\end{tabular}

Letras diferentes na mesma linha indicam diferença significativa pelo teste de Tukey $(p<0,05)$ entre os ambientes.

O tipo celular com maior frequência nos ambientes foi o de linfócitos, seguido de monócitos, neutrófilos e basófilos. Segundo Tavares-Dias et al. (2002), os linfócitos são as células mais frequentes no sangue periférico dos peixes. Ranzani-Paiva e Silva-Souza (2004), também relatam que estas células são os tipos mais frequente de leucócitos presentes na circulação de peixes.

Considerando a análise estatística entre as condições ambientais, foi observada diferença significativa $(\mathrm{p}<0,05)$ entre os ambientes apenas para os valores de linfócitos e monócitos, sendo que, em ambos os parâmetros as diferenças foram entre as condições ambientais um e dois e entre dois e três. Apesar das diferenças observadas, os valores encontrados nos ambientes estão de acordo com a variação observada para grupos próximos à espécie (TAVARES-DIAS; MORAES, 2004).

Em situação de estresse os peixes podem responder de diferentes formas. Martins et al. (2002) avaliaram a frequência de linfócitos em tambacus após serem expostos ao estresse, sendo observado a diminuição destas células. Tavares-Dias et al. (2001), observaram o inverso em tambaquis capturados e expostos a um agente estressor.

Foi observada durante a contagem diferencial a presença de linfócitos com tamanhos distintos (Figura 4). Segundo Beelen et al. (1998), linfócitos "grandes" são células jovens e os linfócitos "pequenos" células maduras. Para Lewis et al. (1979), os "pequenos" linfócitos são análogos aos linfócitos $\mathrm{T}$ de mamíferos, com receptores de superfície para eritrócitos, enquanto os linfócitos “grandes" são análogos aos linfócitos B, apresentando imunoglobulinas de superfície.

\section{Figura 4 - Observação de linfócitos (Lf) com tamanhos distintos, grandes (G) e pequenos $(P)$ presente na circulação de sangue periférico de Astyanax bimaculatus.}

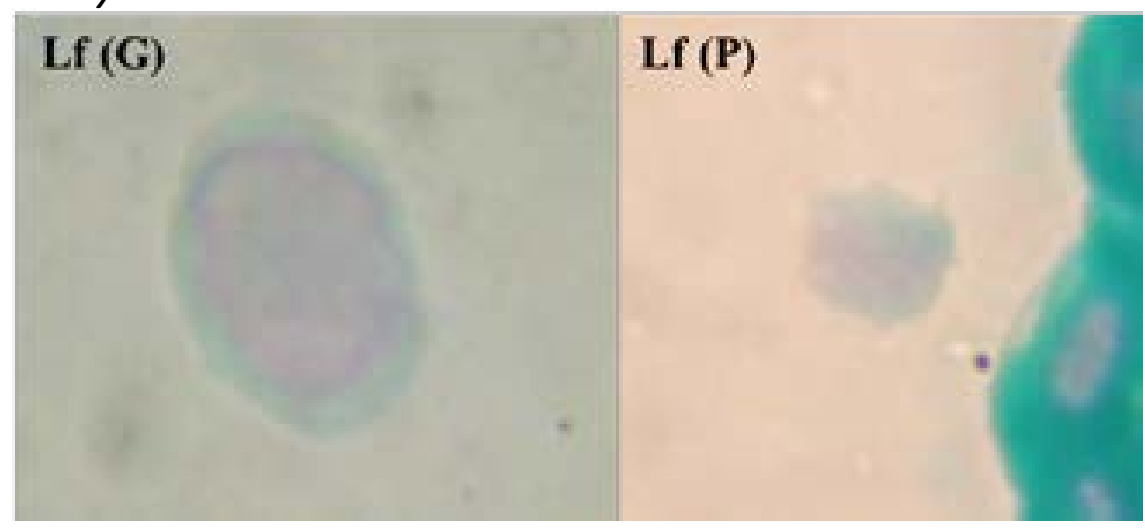

Fonte: Oliveira. 
Em peixes saudáveis, os leucócitos estão presentes em proporções e locais específicos, e representam a primeira linha de defesa contra patógenos (ADAMS et al., 2010). Sua atividade fisiológica é condicionada à capacidade de realizarem migração seletiva e diapedese (RANZANIPAIVA; SILVA-SOUZA, 2004).

Os resultados apresentados mostram que os indivíduos utilizados mantiveram uma boa condição de saúde durante o período de estudo, estando os parâmetros observados dentro dos valores estabelecidos em literatura.

\section{Conclusões}

A busca para se estabelecer protocolos mais eficientes e rápidos para uma análise in situ de ambientes aquáticos são importantes, e diversos estudos foram desenvolvidos para o monitoramento de populações de peixes nos ambientes naturais e em cultivo.

A aplicação das técnicas de avaliação da genotoxicidade, teste do micronúcleo e de anomalias nucleares, foram eficazes para o monitoramento de exemplares de $A$. bimaculatus mantidos em diferentes condições ambientais. A contagem diferencial de elementos da série branca do sangue periférico foi uma metodologia eficiente para demonstrar as condições de saúde dos animais durante o estudo.

Com base nesta pesquisa foi possível observar que as metodologias utilizadas podem ser aplicadas em estudos de monitoramento de atividades de cultivo de organismos aquáticos, considerando o modelo experimental que possuía semelhança aos modelos de produção aquícola (pisciculturas em tanque artificial), além de possibilitar que tais metodologias sejam utilizadas em estudos de monitoramento de ambientes naturais.

\section{Referências}

ADAMS, D. H.; SONNE, C.; BASU, N.; DIETZ, R; NAM, D. H.; LEIFSSON, P. S.; JENSEN, A. L. Mercury contamination in spotted seatrout, Cynoscion nebulosus: an assessment of liver, kidney, blood, and nervous system health. Science of the total environment, v. 408, n. 23, p. 5808-5816, 2010.

AL-SABTI, K.; METCALFE, C.D. Fish micronuclei for assessing genotoxicity in water. Mutation Research, v. 343, p. 121-135, 1995.

ANBUMANI, S.; MOHANKUMAR, Mary N. Gamma radiation induced micronuclei and erythrocyte cellular abnormalities in the fish Catla catla. Aquatic Toxicology, v. 122, p. 125-132, 2012.

ARAGÃO, M.A; ARAÚJO, R.P.A. Métodos de Ensaios de Toxicidade com Organismos Aquáticos. In: ZAGATTO, P. A.; BERTOLETTI, E. (Org.) Ecotoxicologia Aquática: Princípios e Aplicações. São Carlos: RIMA, 2008.

AYRES, M.; AYRES JR, Ayres D1; SANTOS, A. S. BioEstat 5.3 v: aplicação estatísticas nas áreas das ciências biológicas e médicas. Belém, Brasil: Sociedade Civil Mamirauá, p. 193, 2011. 
BARŠIENĖ, J.; BJORNSTAD, A.; RYBAKOVAS, A.; ŠYVOKIENĖ, J.; ANDREIKĖNAITÉ, L. Environmental genotoxicity and cytotoxicity studies in mussels and fish inhabiting northern Atlantic zones impacted by aluminum industry. Ekologija, v. 56, n. 3, p. 116-123, 2010.

BASTOS, J. R. Sobre a serie vermelha do sangue de Scomberomorus maculatus (Mitchill). Arquivos Estação de Biologia Marinha da Universidade Federa do Ceará, v. 6, n. 1, p. 39- 45, 1966.

BEELEN, R.; VAN DER HEIJDEN, T.; VERDEGEM, M.; PAVANELLI, G. C. Blood values of young Brazilian catfish Pseudoplatystoma corruscans (Agassiz, 1829). Acta Scientiarum, v. 20, n. 2, p. 147-150, 1998

BEKETOV, M. A.; LIESS, M. Ecotoxicology and macroecology - Time for integration. Environmental Pollution, v. 162, p. 247-254, 2012.

BOLEDA, M. R.; GALCERAN, M. T.; VENTURA, F. Monitoring of opiates, cannabinoids and their metabolites in wastewater, surface water and finished water in Catalonia, Spain. Water Research, v. 43, p. 126-36, 2009.

BOLLER, K.; SCHMID, W. Chemische mutagenese beim Säuger. Das knochenmark des Chinesischen hamsters als in vivo-Testsystem. Hämatologische befunde nach behandlung mit trenimon. Humangenetik, v. 11, n. 1, p. 35-54, 1970.

BOLOGNESI, C.; CIRILLO, S. Genotoxicity biomarkers in aquatic bioindicators. Current Zoology, v. 60, n. 2, p. 273-284, 2014.

BOPP, K. S.; ABICHT, H. K.; KNAUER, K. Copper-induced oxidative stress in rainbow trout gill cells. Aquatic Toxicology, v. 86, p. 197-204, 2008.

BOTELHO, R. G.; MONTEIRO, S. H.; CHRISTOFOLETTI, C. A.; MOURAANDRADE, G. C. R.; TORNISIELO, V. L. Environmentally relevant concentrations of atrazine and ametrine induce micronuclei formation and nuclear abnormalities in erythrocytes of fish. Archives of environmental contamination and toxicology, v. 69, n. 4, p. 577-585, 2015.

BRAHAM, R. P.; BLAZER, V. S.; SHAW, C. H.; MAZIK, P. M. Micronuclei and other erythrocyte nuclear abnormalities in fishes from the Great Lakes Basin, USA. Environmental and molecular mutagenesis, v. 58, n. 8, p. 570-581, 2017.

CAMPANA, M. A.; PANZERI, A. M.; MORENO, V. J.; DULOUT, F. N. Genotoxic evaluation of the pyrethroid lambda-cyhalothrin using the micronucleus test in erythrocytes of fish Cheirodon interruptus interruptus. Mutation Research, v. 438, p. 155-161, 1999. 
CARRASCO, K. R.; TILBURY, K.L.; MYERS, M.S. Assessment of the piscine micronucleus test as an in situ biological indicator of chemical contaminant effects. Canadian Journal of Fisheries and Aquatic Sciences, v. 47, n. 11, p. 2123-2136, 1990.

CARROLA, J.; SANTOS, N.; ROCHA, M. J.; FONTAINHAS-FERNANDES, A.; PARDAL, M. A.; MONTEIRO, R. A.; ROCHA, E. Frequency of micronuclei and of other nuclear abnormalities in erythrocytes of the grey mullet from the Mondego, Douro and Ave estuaries - Portugal. Environmental Science and Pollution Research, v. 21, n. 9, p. 6057-6068, 2014.

CAVALCANTE, D. G. S. M.; MARTINEZ, C. B. R.; SOFIA, S. H. Genotoxic effects of Roundup ${ }^{\circledR}$ on the fish Prochilodus lineatus. Mutation Research/Genetic Toxicology and Environmental Mutagenesis, v. 655, n. 1, p. 41-46, 2008.

ÇAVAS, T.; KONEN, S. Detection of cytogenetic and DNA damage in peripheral erythrocytes of gold fish (Carassius auratus) exposed to a glyphosate formulation using the micronucleus test and the comet assay. Mutagenesis, v.22, p. 263-268, 2007.

FERRARO, M. V.M.; FENOCCHIO, A. S.; MANTOVANI, M. S.; RIBEIRO, C. O.; CESTARI, M. M. Mutagenic effects of tributyltin and inorganic lead (Pb II) on the fish Hoplias malabaricus as evaluated using the comet assay and the piscine micronucleus and chromosome aberration tests. Genetics and Molecular Biology, v. 27, n. 1, p. 103-107, 2004.

GALINDO, T.P.; MOREIRA, L. M. Evaluation of genotoxicity using the micronucleus assay and nuclear abnormalities in the tropical sea fish Bathygobius soporator. Genetics and Molecular Biology, v. 32, n. 2, p. 394-398, 2009.

GALLOWAY, T. S.; COLE, M.; LEWIS, C. Interactions of microplastic debris throughout the marine ecosystem. Nature ecology \& evolution, v. 1, n. 5, p. 0116, 2017.

GINEBREDA, A.; KUZMANOVIC, M.; GUASCH, H.; ALDA, M. L.; LÓPEZDOVAL, J. C., MUÑOZ, I.; ... BARCELÓ, D. Assessment of multi-chemical pollution in aquatic ecosystems using toxic units: compound prioritization, mixture characterization and relationships with biological descriptors. Science of the total environment, v. 468, p. 715-723, 2014.

GRASSI, L. E. A. Hematologia, Biometria, Teor de compostos organoclorados e Frequência de formação de micronúcleos em teleósteos de água doce, sob diferentes condições liminológicas. 2002. 166 f. Tese (Doutorado em Ciências Biológicas). Universidade Estadual Paulista "Julio de Mesquita Filho", Rio Claro, 2002. 
HALLARE, A. V.; OCAMPO, K. A. A.; TAYO, P. K. S.; BALOLONG, M. M. Genotoxic stress induced by intensive aquaculture activities in Taal lake (Philippines) on circulating fish erythrocytes using the comet assay and Micronucleus Test. Advances in Environmental Biology, v. 10, n. 1, p. 273-283, 2016.

HENRY, M.; GASCO, L.; PICCOLO, G.; FOUNTOULAKI, E. Review on the use of insects in the diet of farmed fish: past and future. Animal Feed Science and Technology, v. 203, p. 1-22, 2015.

HOOFTMAN, R. N. de RAAT, W. K. Induction of nuclear anomalies (micronuclei) in the peripheral blood erythrocytes of the eastern mudminnow Umbra pygmea by ethyl methanesulphonate. Mutation Research, v. 104, p.147-152, 1982.

JERÔNIMO, G.T.; BRUM, A.; PÁDUA, S. B. D.; GONÇALVES, E. L.T.; CAPECCI, R. S.; ISHIKAWA, M. M.; MARTINS, M. L. Haematological Parameters of the Hybrid Surubim (Pseudoplatystoma reticulatum $\times$ P. corruscans) farmed in Brazil. Brazilian Archives of Biology and Technology, v. 58, n. 2, p. 254-261, 2015.

LEWIS, D. H.; EURELL, T. E.; CANNON, M. S.; GRUMBLES, L. C.T and B cell analogues from peripheral blood of immune channel catfish, Ictalurus punctatus. Journal of Fish Biology, v. 14, n. 1, p. 31-37, 1979.

MARTINS,M.L.; MORAES, F.R.; FUJIMOTO, R.Y.; NOMURA,D.T.; FENERICK JUNIOR, J. Respostas do híbrido tambacu (Piaractus mesopotamicus Holmberg, 1887, macho x Colossoma macropomum Cuvier, 1818, fêmea) a estímulos simples e consecutivos de captura. Boletim do Instituto de Pesca, v. 28, p. 195-204, 2002.

MELO, K.M.; ALVES, I. R.; PIECZARKA,J.C.; DAVID, J.A. D. O.; NAGAMACHI, C.Y.; GRISOLIA, C.K. Profile of micronucleus frequencies and nuclear abnormalities in different species of electric fishes (Gymnotiformes) from the Eastern Amazon. Genetics and molecular biology, v. 36, n. 3, p. 425-429, 2013.

MORAIS, I. S.; AZEVEDO, J. S. O uso da microanálise em otólitos de bagres bioindicadores em estudos de biomonitoramento ambiental. Biota Amazônia, v. 7, n. 2, p. $65-77,2017$.

NAN,P.;XIA,X.H.; DU, Q.Y.; CHEN,J.J.;WU,X.H.; CHANG,Z.J. Genotoxic effects of 8-hydroxylquinoline in loach (Misgurnus anguillicaudatus) assessed by the micronucleus test, comet assay and RAPD analysis. Environmental toxicology and pharmacology, v. 35, n. 3, p. 434-443, 2013.

OBA-YOSHIOKA, E. T.; COSTA, R.; BORGES, M.; TAVARES-DIAS, M. Blood variables of hybrid tambacu farmed in Amapá state, Northern Brazil. Veterinária e Zootecnia, v. 24, n. 1, p. 201-208, 2017. 
OMAR, W. A.; ZAGHLOUL, K. H.; ABDEL-KHALEK, A. A.; ABO-HEGAB, S. Genotoxic effects of metal pollution in two fish species, Oreochromis niloticus and Mugil cephalus, from highly degraded aquatic habitats. Mutation Research/Genetic Toxicology and Environmental Mutagenesis, v. 746, n. 1, p. 7-14, 2012.

OSMAN, A. G. M.; HARABAWY, A. Hematotoxic and genotoxic potential of ultraviolet-A radiation on the African catfish Clarias gariepinus (Burchell, 1822).Journal of Fisheries International, v. 5, n. 3, p. 44-53, 2010.

PHAN, V. N.; GOMES, V.; PASSOSC, M. J. A. C. R.; ROCHAD, A. J. S. In vivo micronucleus test for detecting response of teleost fish to environmental genotoxic exposure. Fish Cytogenetic Techniques: Ray-Fin Fishes and Chondrichthyans, p. $175,2015$.

PITOMBEIRA, M. S.; MARTINS, J. M. A direct method for white blood cell count in fishes. Arquivos Estação de Biologia Marinha da Universidade Federa do Ceará, v. 6, n. 2, p. 205, 1966.

POLLO, F. E.; BIONDA, C. L.; SALINAS, Z. A.; SALAS, N. E.; MARTINO, A. L. Common toad Rbinella arenarum (Hensel, 1867) and its importance in assessing environmental health: test of micronuclei and nuclear abnormalities in erythrocytes. Environmental monitoring and assessment, v. 187, n. 9, p. 581, 2015.

RANZANI-PAIVA, M. J. T. Estudos hematológicos em curimbatá, Prochilodus scrofa Steindacher (Osteichthyes, Cypriniformes, Prochilodontidae). 1981.119f. Dissertação (Mestrado em Ecologia e Recursos Naturais). São Carlos, Universidade Federal de São Carlos, 1981.

RANZANI-PAIVA, M.J.T.; SILVA-SOUZA, A.T. Hematologia de Peixes Brasileiros, p.89-120. In: RANZANI-PAIVA, M. J. T.; TAKEMOTO, R. M.; LIZAMA M. L. A. P. Sanidade de Organismos Aquáticos. São Paulo: Varela, 2004.

RIVERO-WENDT, C. L. G.; MIRANDA-VILELA, A. L.; FERREIRA, M. F. N.; AMORIM, F. S., DA SILVA, V. A. G.; LOUVANDINI, H.; GRISOLIA, C. K. Lack of genotoxicity in Astyanax bimaculatus and Oreochromis niloticus of $17 \alpha$-methyltestosterone used in fish hatcheries to produce male monosex populations. Genetics and molecular research: GMR, v. 12, n. 4, p. 5013, 2013.

ROBERTS, R. J. Patologia de los peces. Madri: Ediciones Mundi-Prensa, 1981.

ROCHA, C.A.M.; CUNHA, L.A.; PINHEIRO, R.H.S.; BAHIA, M.O.; BURBANO, R. M. R. Studies of micronuclei and other nuclear abnormalities in red blood cells of Colossoma macropomum exposed to methylmercury. Genetics and Molecular Biology, v. 34, n. 4, p. 694-7, 2011. 
SALVADORI, D.; RIBEIRO, L.; FENECH, M. Teste do micronúcleo em células humanas in vitro. In: RIBEIRO, L. M.; SALVADORI, D. M. F.; MARQUES, E. K. Mutagênese Ambiental. Canoas: ULBRA, 2003, 355 p.

SANTOS, L. H.; ARAÚJO, A. N.; FACHINI, A.; PENA, A.; DELERUE-MATOS, C.; MONTENEGRO, M. C. B. S. M. Ecotoxicological aspects related to the presence of pharmaceuticals in the aquatic environment. Journal of hazardous materials, v. 175, n. $1-3$, p. $45-95,2010$

SCHMID, W. The micronucleus tests. Mutation Research, v. 31, n. 1, p. 9-15, 1975.

SILVA, S. V. S.; DIAS, A. H. C.; DUTRA, E. S.; PAVANIN, A. L.; MORELLI, S.; PEREIRA, B. B. The impact of water pollution on fish species in southeast region of Goiás, Brazil. Journal of Toxicology and Environmental Health, Part A, v. 79, n. 1, p. 8-16, 2016.

SOUZA, J. R.; MORAES, M. E. B.; SONODA, S. L.; SANTOS, H. C. R. G. A importância da qualidade da água e os seus múltiplos usos: caso Rio Almada, sul da Bahia, Brasil. REDE-Revista Eletrônica do Prodema, v. 8, n. 1, 2014.

SUMMAK, S.; AYDEMIR, N. C.; VATAN, O.; YILMAZ, D.; ZORLU, T.; BILALOGLU, R. Evaluation of genotoxicity from Nilufer Stream (Bursa / Turkey) water using piscine micronucleus test. Food and Chemical Toxicology, v. 48, p. 2443-2447, 2010.

SVOBODOVA,Z.;PRAVDA,D.;PALACKOVA,J.Unified Methods of Haematological Examination of Fish. Methods No 20. Vodnany, Czech Republic: Research Institute of Fish Culture and Hydrobiology; 1991.

TAVARES-DIAS, M.; MARTINS M. L.; SCHALCH, S. H. C.; ONAKA, E. M.; QUINTANA, C. I. F.; MORAES, J. R. E.; MORAES, F. R. Alterações hematológicas e histopatológicas em pacu, Piaractus mesopotamicus Holmberg, 1887 (Osteichthyes, Characidae), tratado com sulfato de cobre (CuSO4). Acta Scientiarum, v. 24, n. 2, p. 547-554, 2002.

TAVARES-DIAS, M.; MORAES, F. R. Hematologia de peixes teleósteos. Ribeirão Preto: Villimpress, 2004, 144p.

TESKE, E. Leukocytes. In: WEISS, D. J.; WARDROP, K. J. Veterinary hematology. Iowa: Blackwell Publishing Ltd, 2010,1.206 p.

TUREK, J.; CASTILHOS-GHISI, N.; MATOZO, F.; NOLETO, R. B. Efeitos citotóxicos de um herbicida a base de glifosato no peixe Astyanax altiparanae. Luminária, v. 19, n. 02, 2018. 
UMBUZEIRO, G. A.; ROUBICEK, D. A. Genotoxicidade Ambiental. In:ZAGATTO, P. A.; BERTOLETTI, E (Org.). Ecotoxicologia Aquática: Princípios e Aplicações. São Carlos: Rima, 2008, 472 p.

VÖRÖSMARTY, C. J.; MCINTYRE, P. B.; GESSNER, M. O.; DUDGEON, D.; PRUSEVICH, A.; GREEN, P.; ... DAVIES, P.M. Global threats to human water security and river biodiversity. Nature, v. 467, n. 7315, p. 555, 2010.

WALIA, G. K.; HANDA, D.; KAUR, H.; KALOTRA, R. Ecotoxicological studies on fish, Labeo rohita exposed to tannery industry effluent by using micronucleus test. The Nucleus, v. 58, n. 2, p. 111-116, 2015.

ZAGATTO, P. A.; BERTOLETTI, E. Ecotoxicologia Aquática: Princípios e Aplicações. São Carlos: Rima, 2008, 472 p. 